\title{
Impact of European Water Framework Directive Article 7 on Drinking Water Directive Compliance for Pesticides: Challenges of a prevention-led approach
}

Dolan, T. ${ }^{a^{*}}$, Howsam, P. ${ }^{a}$, Parsons, D.J. ${ }^{a}$, Whelan, M.J.,

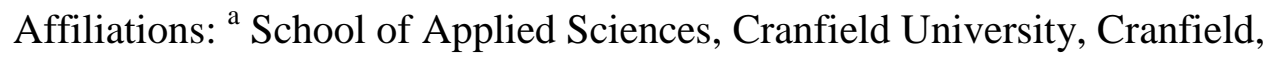
Bedfordshire, UK, MK43 0AL

${ }^{\mathrm{b}}$ Current Address: Department of Geography, University of Leicester, Leicester, UK, LE1 7RH

*Corresponding Author: Tom Dolan, School of Applied Sciences, Cranfield University, Cranfield, Bedfordshire, MK43 0AL

Telephone: $+44(0) 7411340240$

Email: t.e.dolan@cranfield.ac.uk

Fax: $+44(0) 1234752971$ 


\begin{abstract}
Article 7 of the European Water Framework Directive (WFD) promotes a preventionled, approach to European Drinking Water Directive (DWD) compliance for those parameters that derive from anthropogenic influences on raw water quality. However, the efficacy of pollution prevention interventions is currently uncertain and likely to be variable, which makes absolute compliance with the drinking water standard a significant challenge. Member State governments, the WFD competent authority, the DWD competent authority, water companies and agriculture are all affected by and have a different perspective on the nature of this challenge. This paper presents a discussion of these perspectives applicable to stakeholders in all EU Member States; the analysis is supported with examples from England and Wales. Improved understanding of the challenges faced by each group is needed if these groups are to achieve the shared goals of WFD Article 7 compliance and DWD compliance without a disproportionately negative impact on agricultural productivity. In addition, the European Commission needs to be aware of and address a potential incompatibility between WFD Article 7 and the DWD. With this in mind, targeted recommendations for action are presented for each stakeholder group.
\end{abstract}

\title{
Keywords
}

Pesticides, Potable Water, Diffuse Pollution, Stakeholders, Regulation, Legislation, Europe, Metaldehyde, Water Framework Directive, Drinking Water Directive 


\section{Introduction}

While integrated water management is a widely accepted goal in many countries, a fully integrated legal framework to support this goal does not yet exist. For example, in Europe different regimes apply to environmental water quality and drinking water quality. Legislation to manage environmental waters (Water Framework Directive: WFD EC, 2000), i.e. the source of the raw waters used in drinking water supplies, remains distinct from legislation on the quality of drinking water, defined in the European Drinking Water Directive (DWD) (EC, 1998).

In Europe, drinking water is produced, to standards defined in the DWD, using water abstracted from the environment. Treatment to remove pollution and strategies to prevent pollution are used to ensure a wholesome supply of drinking water. The WFD was introduced 'to establish a framework for the protection of inland surface waters, transitional waters, coastal waters and groundwater' (WFD Article 1.) Article 7 of the WFD is focused on bodies of water used for drinking water supply, meeting DWD standards through prevention of deterioration in raw water quality and minimising the extent to which additional treatment is necessary.

Using pesticides as an example, this paper describes how, for certain water quality parameters, WFD Article 7 is driving an increasingly prevention-led approach to DWD compliance, and examines the potential challenges faced by Member State governments, WFD competent authorities, DWD competent authorities, water companies and agriculture, when implementing this approach to DWD compliance. 
In order to set the context for subsequent discussion, the paper includes an overview of DWD standards, an explanation of the significance of WFD Article 7 for all pesticide active substances, and proposes a framework for assessing the efficacy of pollution prevention interventions. The paper concludes with targeted recommendations for stakeholders affected by WFD Article 7 and the European Commission.

Throughout the paper, examples from England and Wales are used to support the analysis. The examples given are partially shaped by the underlying structure of the water industry in England and Wales, and a prevailing UK preference for environmental protection through voluntary actions. Nevertheless, the challenges illustrated are analogous to the situation in other European countries because the nature of the challenge is primarily driven by the common need to comply with both the WFD Article 7 and the DWD.

While the focus of the paper is pesticides in the potable water supply, the analysis is also relevant for other parameters included in the DWD for which diffuse pollution is a significant contributor to the risk of non-compliance.

\section{Water Framework Directive (WFD) Article 7}

The requirements for the protection of water supply abstractions are often different to those for protection of aquatic biodiversity (Breach, 2011). WFD Article 7 on 'Waters used for the abstraction of drinking water' (EC, 2000) recognises this distinction. Article 7.1 requires that 'Member States identify all bodies of water used for the 
abstraction of water intended for human consumption'. Article 7.2 specifies 'that under the water treatment regime applied, and in accordance with Community legislation, the resulting water will meet the requirements of Directive 80/778/EEC (EC, 1980) as amended by Directive 98/83/EC [the DWD]'. Article 7.3 specifies that 'Member States shall ensure the necessary protection for the bodies of water identified with the aim of avoiding deterioration in their quality in order to reduce the level of purification treatment required in the production of drinking water'. Therefore, in designated protected areas, WFD Article 7 promotes DWD compliance for certain key parameters through preventative actions to avoid deteriorating raw water quality, rather than through investment in additional treatment infrastructure or increased process intensity (operating demand). The competent authority for the WFD must achieve this compliance in all Article 7 protected areas by 2015 (EC, 2000). This cannot be derogated beyond 2015 (Kennedy et al., 2009).

In the protected areas designated under Article 7.1, known in the UK as drinking water protected areas (DrWPA), WFD Article 7 applies to all pesticide active substances. For surface water bodies, the targets set by WFD Article 7 are independent of ecological, chemical, and hydromorphological status targets. Thus, it is possible for a surface water body to achieve "good status" while failing WFD Article 7 and vice versa. This is not the case for ground water where WFD Article 7 is not distinct from chemical and quantitative status targets.

Chemical status and ecological status targets apply to all surface water bodies. However, only those active substances for which environmental quality standards (EQS) have been set can affect compliance. In 2015, at the end of the first River Basin 
Management Plan (RBMP) cycle, EQS values will apply to just six currently approved pesticide active substances. Two are the Article 4 priority substances chlorpyrifos and diuron (EC, 2008); EQSs for these will apply across all EU member states. The remaining four are the 'specific pollutants' cypermethrin, dimethoate, 24,D and linuron (UKTAG, 2008a), for which EQSs will apply in the UK only (unless other Member States also decide to classify them in the same way).

Under a European Commission proposal (COM(2011)876) on priority substances (EC, 2012), six additional pesticide active substances (cybutryne, aclonifen, bifenox, cypermethrin, heptachlor and quinoxyfen) will be classed as priority substances with EQSs defined and applicable before the end of the second RBMP in 2021. In the UK, following a stakeholder consultation, the UK Technical Advisory Group (UKTAG) identified five further active substances - carbendazim, methiocarb, chlorothalonil, pendimethalin and glyphosate - as 'specific pollutants'; for which EQSs will apply from the start of the second RBMP cycle in 2015 (UKTAG, 2012). Because 'specific pollutants' are defined by each Member State, the range of specific pollutants subject to an EQS will vary across Europe but the total number of active substances subject to EQSs is likely to remain small relative to the 411 active substances currently approved in Europe under Reg. 1107/2009 (Directorate General for Health and Consumers, 2012), all of which are subject to WFD Article 7.

Furthermore, the pesticide active substances subject to WFD status targets are largely different from those 'at risk' of causing WFD Article 7 non-compliance. In England and Wales, the Environment Agency (EA) has twice assessed pesticide active substances deemed to be 'at risk' of causing non-compliance for WFD Article 7 in 
one or more surface water bodies. In the first assessment (Kennedy, 2010) the EA identified 41 active substances as 'at risk' of causing WFD Article 7 non compliance in one or more DrWPA. Of these, 30 remain approved for use under European pesticide legislation (EC, 1991, EC, 2009). Of these 30, metaldehyde, MCPA, chlortoluron, mecoprop, carbetamide, 2,4-D, propyzamide and asulam, none of which has an EQS assigned, each cause 'at risk' status in ten or more DrWPAs in England and Wales. At the time of writing, results from the second EA assessment have yet to be published.

\section{Drinking Water Directive (DWD)}

Annex I (part B) of the DWD (Directive 98/83/EC) (EC, 1998) specifies that all potable water supplied in Europe must not contain any individual pesticide active substance at a concentration greater than $0.1 \mu \mathrm{g} / \mathrm{l}$ at the point of consumption (a lower value of $0.03 \mu \mathrm{g} / \mathrm{l}$ is applied for four active substances aldrin, dieldrin, heptachlor and heptachlor epoxide). Furthermore, the maximum concentration of total pesticides is $0.5 \mu \mathrm{g} / \mathrm{l}$. Since these standards are maximum allowable concentrations (MACs) rather than Annual Averages (AA) or percentile values they must never be exceeded. It follows that there is no concept of acceptable risk for pesticides in European drinking water.

These standards were first set for total pesticides in Directive 75/440/EEC (EC, 1975) and for individual pesticide active substances in Directive 80/778/EEC (EC, 1980). When the standards were set, the EC adopted a precautionary approach, because little was known about chronic long term effects of pesticides (Jordan, 1999). The purpose 
of the standard was to avoid the presence of pesticides in European potable water. DWD standards are, therefore, not based upon toxicological data (Croll, 1995) and are effectively surrogates for zero since $0.1 \mu \mathrm{g} / \mathrm{l}$ was typical of analytical limits of detection when the standard was first introduced (Knapp, 2005).

Despite a requirement for a rolling five year review in the light of scientific and technical progress (DWD Article 11.1), the standards for pesticides have remained unchanged from when they were first introduced. Although a further review is expected in 2013 a change in standards is not expected (see Dolan et al., 2013) and for the purpose of discussion in this paper it is assumed that any reference to the DWD in WFD Article 7 is to the $0.1 \mu \mathrm{g} / \mathrm{l}$ standard defined in the current Annex 1 of the DWD.

\section{Discussion: WFD Article 7, a prevention-led approach to DWD compliance}

\subsection{Introduction}

Water suppliers are legally responsible for supplying DWD-compliant potable water. The need for $100 \%$ compliance with the precautionary standards in the DWD and the absence of a concept of acceptable risk create a 'compliance/legal risk' for potable water suppliers (Pollard et al., 2004). It follows that a water supplier will take action to minimise the risk of non-compliance as much as possible. Failure to do so would leave a water supplier at risk of non-compliance with DWD standards and the member state potentially at risk of failure to comply with WFD Article 7.

There are two primary routes to ensure DWD compliance: 
(1) Water treatment to reduce active substance concentrations to below the MAC and

(2) Prevention of pesticide movement to raw waters used for drinking water abstraction.

Treatment is an intervention that water companies can control. The installation of sufficient treatment capacity will give a water supplier certainty that the risk of noncompliance with the DWD will be close to zero. By contrast, most pollution prevention strategies (which might include structural measures, such as designating buffer zones near to water courses or constructing attenuation ponds in the drainage ditch network, as well as non-structural approaches, such as changes in pesticide application regimes or crop rotations) are harder for water companies to implement because they have little experience of implementation, and minimal control over land use and agricultural practice in their catchments (Keirle and Hayes, 2007; Dolan et al., 2012). Furthermore, the efficacy of such measures are often uncertain and are likely to be variable temporally (e.g. with weather patterns) and spatially (e.g. with different soil types over a catchment) (Reichenberger et al., 2007). Finally, it is especially difficult to ensure completely effective protection in larger, more complex catchments (Breach, 2011).

\subsection{Preference for Treatment}

In practice, an approach to DWD compliance based primarily on treatment has historically been adopted by water suppliers. This approach is more resilient to variations in raw water quality caused by the actions of other catchment stakeholders or by fluctuations in weather conditions. In England and Wales, this preference for treatment was reflected in a high level of capital investment at many water treatment works (WTWs) during the first business cycle (1990-1995) after privatisation (The 
Director General of Water Services, 1991) and a bias toward capital expenditure in the regulatory system leading to the promotion of treatment over catchment based interventions (Ofwat, 2011).

It is important to note, however, that in some circumstances DWD compliance cannot be achieved through treatment alone. For example, this may be the case where high seasonal peak concentrations of a pesticide active substance are present in raw water above concentrations that are treatable with the installed treatment processes (UKWIR, 2011), or where difficult-to-treat active substances such as metaldehyde (Autin et al., 2013) and clopyralid (Tizaoui et al., 2011) are periodically present in raw water at concentrations which exceed the DWD MAC. In these cases, employing catchment management interventions may play a role in supporting existing treatment to achieve compliance.

\subsection{Emphasis on Prevention}

WFD Article 7 challenges the preference for treatment interventions because, through Article 7.3, it promotes prevention in favour of treatment. WFD Article 7 objectives are achieved by delivering DWD compliance at tap (Article 7.2) provided none of the following actions have been taken to compromise Article 7.3 compliance (UK Technical Advisory Group (UKTAG, 2008b):

- An abstraction (or planned abstraction) of water intended for human consumption has to be abandoned and an alternative used to provide the supply;

- Water abstracted (or planned to be abstracted) has to be blended with water abstracted from another source;

- Additional purification treatment has to be applied; 
- The operating demand on the existing purification treatment system has to be significantly increased.

The words in the bullet points above are a UK interpretation of WFD Article 7. It follows from this interpretation that, if a water supplier takes any of the above actions for DWD compliance, they will trigger a WFD Article 7 failure for the protected area.

By restricting the role which additional treatment (including blending of water from several sources) can play and giving priority to prevention, WFD Article 7 limits the ability of water companies to influence outcomes directly. By highlighting the importance of raw water quality at the point of abstraction it implies that responsibility for DWD compliance should be shared between the WFD competent authority (the EA in England and Wales), water suppliers, all pesticide users in the catchment and the DWD competent authority (the Drinking Water Inspectorate in the UK).

In this paper, it is assumed that the UK interpretation of WFD Article 7 is consistent with that made in other European countries and that the challenges presented by WFD Article 7 and the DWD apply to all water supply undertakers across Europe.

However, the validity of this assumption can be challenged, because WFD Article 7 is somewhat ambiguous and there is, thus, potential for slightly different interpretations of the no deterioration, treatment provision (including blending) and timescale criteria to be transcribed into Member State law. WFD guidance documents published by the European Commission (EC, 2013) do not define these criteria for surface water abstractions. This lack of clarity is, therefore, an issue that needs to be resolved by the 
European Commission to ensure that Article 7 is interpreted consistently across all Member States.

\subsection{A Framework for Assessing Prevention Interventions}

In most water supply catchments DWD compliance is already achieved for most parameters using the suite of treatment technologies currently in place. However, new diffuse-source water pollution problems sometimes arise, either as a consequence of changes to one or more factors that influence pesticide use or simply because existing issues are identified via the introduction of new analytical methods to raw water monitoring programmes. In such cases, increased emphasis on pollution prevention creates the need for intervention programmes in catchments vulnerable to diffuse pollution issues. These interventions can act at both pollutant source and pathway levels to attempt to improve raw water quality and, thereby, ensure DWD compliance is achievable with the current treatment provision (Dolan et al., 2012). If successful, they would deliver WFD Article 7 compliance.

Here, we propose a framework of five criteria (Table 1) that any programme of prevention interventions must satisfy in order to achieve the required improvements in raw water quality.

\section{Include Table 1 here}

Table 1. A framework for assessing prevention interventions in terms of satisfying the requirements of both the DWD and WFD Article 7. 
In addition to satisfying the criteria in Table 1, any programme of interventions must be cost-effective and distribute costs equitably between those stakeholder groups affected.

In water bodies where prevention cannot meet the criteria in Table 1, water suppliers may be vulnerable to DWD failure and the water body may be vulnerable to WFD Article 7 failure. This vulnerability arises from the absolute nature of the DWD, restrictions on increases to treatment provision under WFD Article 7, the fixed timescale of Article 7 and, perhaps most importantly, from aleatory and epistemic uncertainty regarding the efficacy of preventative measures. Whilst some measures are likely to be successful, if implemented at the right scale (e.g. bans or restrictions in pesticide use), the success of others, such as changing the length of the crop rotation, changing cultivation practices, designating buffer zones or constructing attenuation features (e.g. ponds or wetlands on ditch networks) are likely to be variable. This can introduce considerable uncertainty into the probability that a set of measures will help to achieve compliance. This uncertainty is likely to increase in large catchments where a greater number of individual local actors need to engage in the right way in order to achieve catchment-scale success.

\section{Stakeholder Perspectives on the challenges of a prevention-led approach to DWD compliance}

Member State governments and four main stakeholder groups face particular challenges as a direct consequence of WFD Article 7 driving a prevention-led 
approach to DWD compliance (Figure 1). The discussion that follows considers each of these challenges from the perspective of each stakeholder group affected.

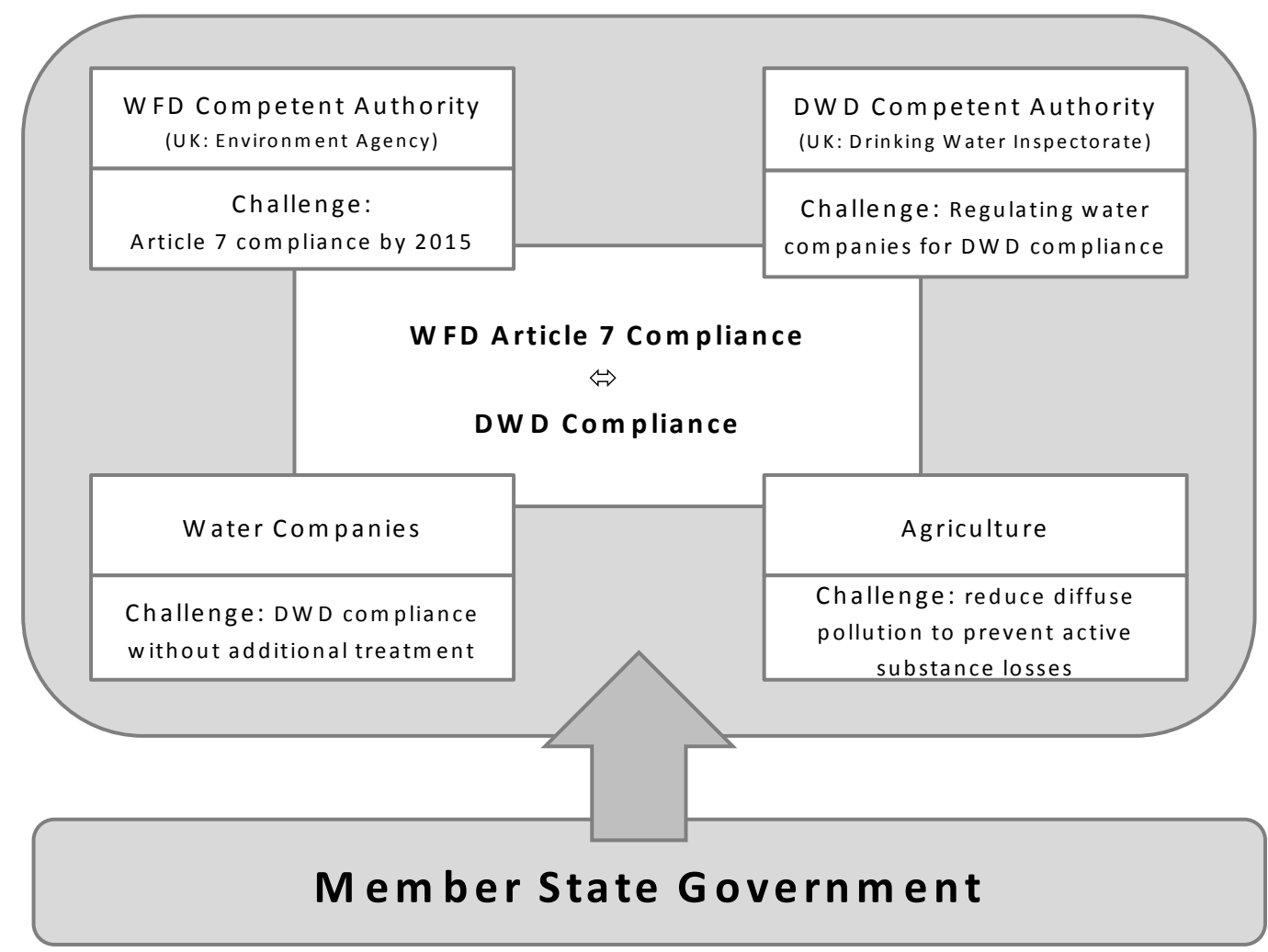

Figure 1. Key stakeholder groups and the challenges posed by an increasingly prevention-led approach to drinking water protection.

\subsection{Member State Government}

Although these challenges (Figure 1) arise from European Directives, the role of Member State governments in shaping and responding to them must not be overlooked. Each government transcribes European Directives into national law, and is ultimately responsible for compliance. Governments have direct influence over all four stakeholder groups, in as much as they establish which authorities are responsible for the WFD and the DWD, they regulate or own the water suppliers and they determine agricultural policy. Government must, therefore, understand the 
significance of the challenges faced by each stakeholder group and take action to support them as appropriate. In particular, it is important to ensure that all stakeholder groups receive clarity and that conflicting objectives do not inhibit the collaboration between groups which may be required to achieve WFD Article 7 and DWD compliance.

\subsection{WFD Competent Authority}

The absolute nature of the DWD and the fixed timescale for WFD Article 7 compliance create challenges for any competent authority aiming to take a risk-based approach to the delivery of cost effective pollution prevention interventions for WFD Article 7 compliance in catchments where diffuse pesticide pollution is an occasional cause of DWD non-compliance.

For each 'at risk' protected area, the competent authority needs to assess the nature and scale of prevention actions required for DWD and WFD Article 7 compliance, and assess whether current action can deliver results that meet the scale, stability, consistency, level of engagement and timeliness criteria in Table 1. Where it is believed that the current measures cannot deliver compliance, further action is required.

WFD competent authorities can choose whether to deliver interventions through statutory or voluntary measures. The need for interventions to be cost-effective and for costs to be distributed equitably between stakeholders must also be acknowledged when determining the balance between voluntary and statutory action. Statutory measures will impose direct and indirect costs on one or more stakeholders in the 
catchment, and may have ramifications for all other activity in the catchment. For example, imposing catchment-specific statutory restrictions on land use or management practices may have a direct cost for farmers should their operating margins be affected but may also have an indirect effect on land value. Voluntary measures typically have lower costs to the stakeholder abating the pollution, but may require cooperation from all stakeholders involved with pesticide use. Regardless of whether the programme of interventions is led by voluntary actions or statutory actions, it needs to be capable of delivering the five criteria in Table 1, in order to satisfy the requirements of the DWD and WFD Article 7.

Assessing whether a particular set of interventions will deliver compliance is not a simple process. All protected areas are different in terms of their physical characteristics, and the spatial and temporal pattern of pesticide use. In addition, the level of prevention actions already initiated, the timescale over which these are expected to deliver and the shortage of information about the expected efficacy of interventions are factors that need to be considered by a competent authority to assess the level of compliance expected in 2015. Literature assessing the efficacy of prevention options highlights the complexity of designing a programme of interventions that satisfies the scale, stability, consistency, level of engagement and timeliness criteria (Table 1). Reichenberger et al. (2007) reviewed the effectiveness and feasibility of the mitigation strategies detailed in 180 papers and concluded that " a compilation of the efficiencies of the mitigation measures available for the different pesticide input pathways is lacking so far." In addition, where pesticides are transferred from land to surface water via drain flow (Brown and van Beinum, 2009; Tediosi et al., 2012) dependable mitigation options are limited to changes in 
application rate and timing, changes in crop rotation or restricted use of an active substance.

A correct assessment for a protected area will support cost effective and timely delivery of compliance with WFD Article 7 through a combination of voluntary and, if necessary, statutory measures and mechanisms. It will also allow clear messages about required actions to be shared with water suppliers and with stakeholders involved with pesticide use. Incorrect assessment of the measures required may lead to either inaction, or over-implementation of prevention actions.

Therefore, an iterative approach involving repeated phases of communication with catchment stakeholders, implementation of prevention actions and assessment of impacts may be required to satisfy the criteria in Table 1 and achieve an optimal balance between compliance and cost effectiveness. A toolkit of well defined measures and mechanisms to implement actions for prevention, as required, would support this approach (Table 2 gives a UK example of this). In addition, research to close the knowledge gaps that exist regarding the efficacy of various prevention options would be useful. Communication is of vital importance because engagement and understanding are needed to support assessment, to identify possible solutions and to implement actions. It is also important that all stakeholders in the catchment are aware of the actions the competent authority is taking and the reasons for these actions. 


\subsubsection{Environment Agency (EA) in England and Wales}

In England and Wales, there is a stated preference to achieve WFD Article 7

compliance through voluntary measures (Kennedy et al., 2009), and avoid increasing the regulatory burden (HM Government, 2011). For this reason the EA, as competent authority, has taken an approach similar to that outlined above. This preference places a constraint on the range of prevention options available to them. Table 2 shows the iterative approach to prevention actions currently being taken by the EA in England and Wales.

\section{Include Table 2 here}

Table 2. An iterative approach for WFD Article 7 compliance in DrWPAs in England and Wales.

Actions to reduce pesticide pollution through behavioural change amongst pesticide users have been led since 2001 by the Voluntary Initiative (VI) (The Voluntary Initiative, 2011). This has had support in some DrWPAs, since 2006, from the England Catchment Sensitive Farming Delivery Initiative (ECSFDI) (Natural England, 2012a) and, since 2009, by the Metaldehyde Stewardship group (MSG) 'Get Pelletwise' campaign for metaldehyde (Metaldehyde Stewardship Group, 2012). However, it is still not known whether these actions will improve raw water to the extent required to meet the scale, stability, consistency, level of engagement and timeliness criteria in Table 1. In particular, and importantly, there are doubts about the stability and consistency of these interventions under certain conditions and about 
whether the scale of reduction and level of engagement required can be achieved within the required timescale in all DrWPAs with potential pesticide issues.

In 2008, the EA examined a number of 'beyond VI' measures for possible use in 'at risk’ DrWPAs (Kennedy et al., 2009). Subsequently, the UK Department for Environment, Food and Rural Affairs (Defra) commissioned further research (Defra, 2012) to identify and appraise cost effective policy instruments to tackle the impacts of pesticides. Furthermore, the EA, the VI and the MSG have identified that provision of simple and locally relevant information to all pesticide users and advisors in the catchment is critical to delivering the level of engagement and scale of improvement required (The Environment Agency, 2012).

Currently, Safeguard Zone Action Plans, as specified in Article 7.3 (EC, 2000), are under development in 'at risk' DrWPAs. In the first instance, these action plans will support targeted deployment of voluntary interventions, provision of local pesticide, water quality and catchment management advice and characterisation of catchments. This will improve understanding of what prevention interventions might be needed in each DrWPA.

If needed, fiscal incentives to encourage appropriate behavioural change in support of WFD Article 7 objectives could be made available. Delivery through an agrienvironment scheme, such as Entry Level Stewardship (ELS) (Natural England, 2012b) would be one possible mechanism for this. Regardless of the delivery mechanism, fiscal incentives must avoid undermining willingness to participate in voluntary actions (Dolan et al., 2012). 
Statutory interventions are seen as a last resort in England and Wales, and would only be used where the need is acute and where cost effective measures were sure to deliver a high certainty of success. However, there is currently little certainty over what statutory actions might be considered.

\subsection{DWD Competent Authority}

The challenge for the DWD competent authority is how to regulate water suppliers during the transition to an increasingly prevention-led approach. Of particular significance are those catchments where current treatment provision does not allow DWD compliance for all active substances. Under Article 9 of the DWD, a derogation (known as an authorised departure in the UK) can be applied for non-compliance with the $0.1 \mu \mathrm{g} / \mathrm{l}$ standard for a pesticide active substance, provided that it does not constitute a potential danger to human health. Derogations are for three years; extension by a further three years requires the Member State to communicate the grounds for the extension to the European Commission (EC, 1998).

The application of a water supplier for a derogation could be seen as indicative of a Member State being non-compliant with WFD Article 7. Therefore, using derogations, except as a temporary measure, is undesirable from the perspective of both the water supplier and the Member State. It follows that derogations are not a substitute for a programme of prevention interventions capable of meeting the criteria proposed in Table 1. 


\subsubsection{The Drinking Water Inspectorate (DWI) In England and Wales}

In England and Wales, the Drinking Water Inspectorate (DWI) is the regulator responsible for ensuring that all water companies comply with the standards specified in the DWD and transcribed into UK law through The Water Supply (Water Quality) Regulations 2000 (HMSO, 2000). The DWI has the power under Regulation 19.1 to grant "undertakings" to allow an authorised departure where a non-trivial failure to meet the pesticide standard is likely to recur. Authorised departures allow temporary non-compliance and require water companies to perform a series of short, medium and long term actions to address each failure.

In some DrWPAs across England and Wales, undertakings are already in place for pesticide active substances (e.g. for metaldehyde and clopyralid). How to manage the renewal of these undertakings in a way which is consistent with both WFD Article 7 and the DWD requirements represents a challenge for the DWI to address along with the EA and the water companies.

\subsection{Water suppliers}

The WFD and DWD are separate European Directives and, therefore, are legally distinct. Compliance with each Directive is the responsibility of a different competent authority. A water supplier has a legal obligation to be DWD compliant $100 \%$ of the time for the potable water they supply. WFD Article 7 appears to make a promise to water suppliers that they will be able to meet DWD standards for some catchmentderived pollutants without the need to make additional investment in treatment infrastructure for potable water production (Figure 2). However, a water supplier cannot be certain that the prevention-led approach, required for WFD Article 7 
compliance, will satisfy the five criteria in Table 1 and give DWD compliance in all WFD Article 7 protected areas. Therefore, the absolute nature of the DWD and WFD Article 7.3 restricting treatment options create a significant challenge for water suppliers.

This challenge should encourage water suppliers to increase investment in pollution prevention actions, such as catchment management, characterising catchments and understanding the agronomic drivers of pesticide use. The need for these types of interventions is further strengthened by the presence of those active substances for which available treatment is ineffective (e.g. metaldehyde and clopyralid), or where high peak concentrations prevent effective removal for DWD compliance.

However, the challenge also creates uncertainty for business planning. In each protected area a water supplier must now consider the consequences to their business of failure to achieve WFD Article 7 compliance (Figure 2), and consider how to mitigate these possible impacts when compiling their business plan. It is assumed here that all water suppliers, whether state or privately owned, undertake some form of business planning for DWD compliance. Therefore, the content of a water supplier's business plan will be inextricably linked to whether a WFD Article 7 protected area is expected to be compliant for pesticide active substances at the end of the first WFD river basin management plan (RBMP) in 2015. If the 2015 target is expected to be met, then minimal investment will be required by the water supplier (Figure 2). If the target is unlikely to be met, then additional expenditure will be needed (Figure 2). Therefore, in order for a water supplier to accurately allocate resources to additional treatment infrastructure, to catchment management plans and to actions as part of a 
safeguard zone management plan, it needs a clear indication, of whether WFD Article 7 compliance will be achieved by 2015 .

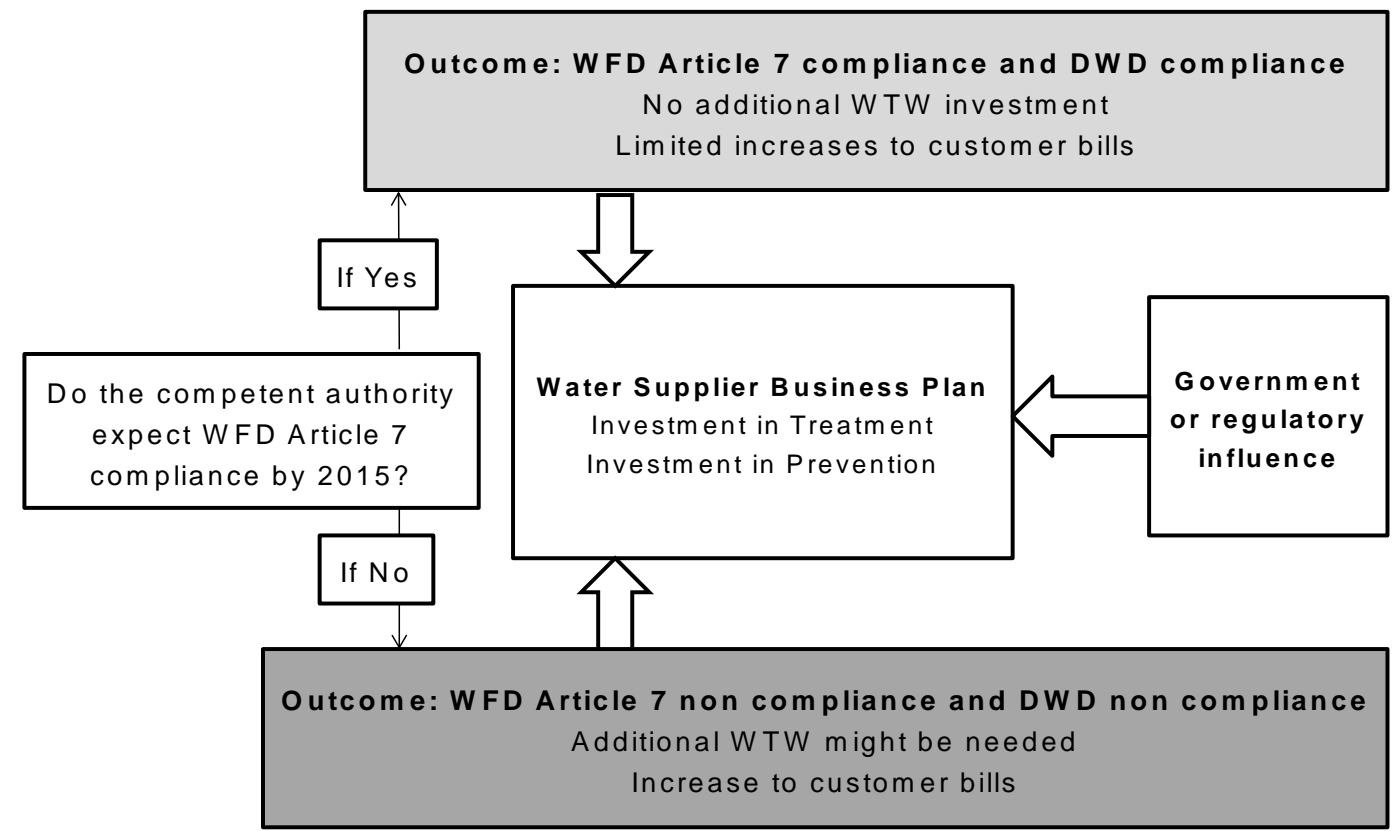

Figure 2. Relationships between WFD Article 7 compliance, DWD compliance and water supplier business planning.

\subsubsection{Water Companies in England and Wales}

In England and Wales, the privately owned, state regulated water companies are obliged to plan investment in five year cycles, known as asset management plans (AMP) and submit a business plan called a Periodic Review (PR) one year before the beginning of an AMP cycle. The next AMP cycle (AMP6) runs from 2015-2020, and the business plan for this cycle (PR14) must be completed early in 2014 . 
When compiling the PR14 business plan, a water company must consider several uncertainties related to regulatory interpretation and competent authority policy. For pesticides, these include: the likelihood of WFD Article 7 non-compliance in a DrWPA; investment to support Safeguard Zones in AMP6; regulatory attitudes toward derogations for DWD non-compliance and additional water company investment in treatment.

Although DrWPAs 'at risk' of Article 7 non-compliance have been identified by the EA, the largely non-structured voluntary actions which have been implemented, thus far, have had uncertain success. In any DrWPA where WFD Article 7 non-compliance is expected in 2015 the EA can: (a) select from options in Table 2 in order to increase the probability of compliance; (b) set alternative objectives and extend compliance until 2021 or 2027, as is allowed for status targets under WFD Article 4 (EC, 2000); or (c) accept non-compliance for a short time period to give current actions time to deliver.

Expectation of which options are to be used will shape how water companies produce their PR14 business plans. Therefore, water companies would benefit from clear EA guidance regarding which of the above options is most likely for each DrWPA 'at risk' of WFD Article 7 non-compliance for pesticide active substances. Similarly, where a safeguard zone action plan is a key component of EA plans for WFD Article 7 compliance in a DrWPA, and water company action and expenditure is needed to support implementation during AMP6, this must be made explicit to the water company as soon as possible, to allow inclusion of actions in PR14. 
In addition, water companies need to know that the positions taken by sector regulators (the DWI and the economic regulator of the UK water industry - Ofwat), will be consistent with decisions taken by the EA. Specifically, water companies need:

- the DWI to define under what WFD Article 7 scenarios, and based upon what evidence, it will grant derogations and/or extend existing derogations for DWD failure for pesticide active substances; and

- Ofwat to specify under what circumstances it will allow a water company to invest in additional treatment infrastructure at PR14.

\subsection{Agriculture}

The fact that the DWD requires $100 \%$ compliance with precautionary standards (see Dolan et al., 2013) for pesticide active substances, the restriction imposed on additional treatment by WFD Article 7.3 and the time-bound nature of WFD Article 7 all present challenges to agriculture. Here, the term agriculture is used to cover farmers, agronomists, pesticide distributors and pesticide manufacturers.

Most current agricultural practices are intended to maximise productivity and gross margins using a range of pesticide active substances from those currently available and approved for use. Any reduction in pesticide availability will potentially have an impact on agricultural productivity. Consultation with agronomists performed as part of this research has identified the types of options potentially available to agriculture when an active substance is lost or restricted (Table 3). Which of these options are workable, and how far down the table agriculture needs to look for a solution is entirely dependent upon the context of the active substance lost or restricted. 
Typically, the further down the table the solution is found, the greater will be the impact on crop yield and gross margin.

\section{Include Table 3 here}

Table 3. Hierarchy of potential responses from agriculture to the loss of a pesticide active substance.

It is important that all stakeholders involved with WFD Article 7 and DWD compliance understand the agricultural perspective on potential restrictions or losses of pesticide active substances. Therefore, agriculture needs to communicate that in practice: (a) direct substitutes are rare; (b) apparent close substitutes or the option for treatment at another stage of the rotation are not only less effective, but in many cases already form a vital part of a resistance management strategy; and (c) non-chemical methods are complements to, rather than substitutes for, pesticide use, because they usually give comparatively poor control at a premium price (Moss, 2010).

\subsubsection{Agriculture in England and Wales}

In England and Wales all plant protection products (PPPs) must be approved by the Chemicals Regulation Directorate (CRD) before use. The CRD set maximum dose rates and have the power to ban any active substance. However, thus far, there is no precedent for pesticide withdrawal in the UK for Article 7 reasons (Dolan et al., 2012), and the EA, as WFD competent authority, view active substance bans as an action of last resort. Nevertheless, the concern remains that WFD Article 7 could 
cause reduced availability of active substances, with associated potential productivity losses for UK agriculture (Wynn et al., 2009; Clarke, 2009; Clarke et al., 2009).

Agriculture in England and Wales is, therefore, focused on (a) protecting the range of active substances currently available; (b) delivering water quality improvements through voluntary actions; and (c) ensuring that the WFD competent authority, other policy makers and water companies are aware of the expected impacts on productivity which a withdrawal or restriction of active substances for WFD Article 7 reasons might cause.

The Voluntary Initiative (VI), the England Catchment Sensitive Farming Delivery Initiative (ECSFDI), and Metaldehyde Stewardship Group (MSG) are all examples of where agriculture has led action to address raw water quality problems. As with all prevention interventions, it has not yet been possible to establish the impact of these actions, and whether they can deliver to the scale, stability, consistency, level of engagement and timeliness criteria (Table 1).

\section{Conclusions and Recommendations}

\subsection{Conclusions}

WFD Article 7 favours a prevention-led approach to DWD compliance for diffuse source pollutants in catchments used for domestic water supply. The need for absolute compliance with a surrogate zero standard for pesticides in drinking water (Dolan et al., 2013) and the uncertainties associated with the efficacy, costs, mode of implementation and equity of prevention interventions (together with the high number of potential actors) make this a significant challenge. Further work is needed to identify solutions in response to this challenge, and to some extent catchment 
management remains "experimental" because the extent to which a prevention-led approach is able to achieve the required reliability of compliance with respect to drinking water quality is currently unknown.

The successful transition to a prevention-led is the collective responsibility of all those groups involved with interpreting and implementing policy at the Member State level, and the European Commission itself, as the body responsible for setting and reviewing legislation. At the Member State level, Government, the WFD competent authority, the DWD competent authority, water companies and agriculture are all affected by, and each have a different perspective on, this challenge. These groups need to share their perspectives and work together to achieve the shared goals of WFD Article 7 compliance, DWD compliance and minimal negative impact on agricultural productivity. At the European level the Commission needs to ensure that the WFD and DWD are consistent with principles of European environmental policy, targets for prevention at source are based on the precautionary principle and available scientific and technical evidence, that sufficient time is allowed for identification and implementation of catchment management solutions, and that the legislative framework does not impose disproportionate costs on agriculture or water suppliers.

\subsection{Recommendations}

The recommendations made in this paper are directed to these groups within each European Member State with the aim of supporting greater clarity, understanding and cooperation between them. The authors acknowledge that some of the recommended actions are already taking place in some Member States. In addition, three recommendations are directed to the European Commission. 
Member State Governments should:

- Define clearly how they interpret the requirements of WFD Article 7, with regard to additional investment in treatment, increased use of existing treatment (including blending), abstraction abandonment and the timescale for compliance.

- Provide a flexible legislative framework to enable the WFD competent authority to implement bespoke programmes of targeted, cost-effective and equitable measures for pollution prevention, as appropriate, in each Article 7 protected area.

- Provide evidence to the European Commission should actions implemented for WFD Article 7 compliance directly increase water prices, reduce agricultural margins or result in other significant costs, including indirect effects such as reductions in land value.

- Engage with the Commission to explore the scientific basis and practicability for introducing a health-based (risk-based) DWD standard for pesticides in drinking water (cf Dolan et al., 2013).

The WFD Competent Authority should:

- Provide clear guidance to water suppliers regarding the authority's position on WFD Article 7 compliance and investment in additional treatment (particularly a clearer definition of what this might include).

- Follow an iterative approach, based upon repeated phases of communication, implementation and assessment, to secure WFD Article 7 compliance.

- Indicate to water suppliers which WFD Article 7 protected areas are expected to be non-compliant in 2015 . 
- Negotiate with water suppliers (and, where applicable, the sector's economic regulator) over the nature and level of investment required for catchment management and safeguard zones that are expected in water suppliers' business plans.

The WFD and DWD Competent Authorities should:

- Facilitate consistent communication with water suppliers and agriculture by developing a mutually consistent position on those WFD Article 7 protected areas which are expected to be non-compliant in 2015.

The DWD Competent Authority should:

- Define the DWD non-compliance conditions under which derogations will be granted to water suppliers to support prevention-led approaches promoted by WFD Article 7.

Water Suppliers should:

- Consult with the WFD competent authority to identify those protected areas where there is the highest risk of Article 7 non-compliance.

- Support the prevention-led approach through targeted investment in actions to understand the risks of diffuse pesticide pollution, the catchment management options which might be available (along with an assessment of their potential to achieve the required outcomes) and safeguard zone action plans.

- Seek guidance on the national position on WFD Article 7 and, particularly, the implications for WFD Article 7 compliance of any investments in new treatment intended to ensure DWD compliance. 
Agriculture should:

- Engage with and initiate industry-wide voluntary actions to support the prevention-led approach to DWD compliance for pesticide active substances.

- Highlight to Member State policy makers (including the WFD competent authority) and water suppliers the significance of key active substances for agricultural productivity, and the potential consequences should any of these substances be banned or restricted.

- Support actions by water suppliers or the WFD competent authority to characterise catchments, understand the risk of diffuse pesticide pollution and attempt to mitigate land to water pesticide transfers.

The European Commission should:

- Provide clearer guidance on WFD Article 7 compliance particularly with respect to investment in additional treatment (including the extent to which blending should be interpreted as a form of treatment in the transposition of the directive into national law), whether the 2015 target for compliance can be derogated to 2021 or 2027 and the meaning of safeguard zones (7.3) for surface water abstractions

- Review whether the interpretation of the DWD MAC as a "red line" (i.e. an absolute threshold which must never be exceeded) could be replaced by a statistical approach based on percentile compliance (e.g. Warn and Brew, 1980; Fristachi et al., 2009). This approach would be more consistent with the prevention-led approach of WFD Article 7, and the inevitably variable efficacy of catchment based interventions (due to the vagaries of the weather etc.) compared to conventional water treatment technologies. 
- Re-examine whether the retention of a uniform DWD MAC standard for all pesticides (and their metabolites), regardless of their different toxicities and modes of toxic action in humans, continues to be consistent with Euorpean Treaty principles (Article 174) on environmental policy (Dolan et al., 2013). These principles, which include the precautionary principle, originally gave rise to the DWD standard for pesticides and are also embedded in the WFD.

- Investigate whether alternative approaches to regulation based on the peerreviewed, risk-based, WHO guidelines for drinking water standards are consistent with European principles for environmental policy.

- Engage in dialogue with the authorities at Member State level which are responsible for implementing WFD Article 7 and a prevention-led approach to DWD compliance. 


\section{Acknowledgements}

The authors would like to acknowledge the support of Anglian Water Services Ltd and EPSRC for funding the EngD research from which this article is produced. Two anonymous referees provided insightful comments which helped to improve the paper. 


\section{References}

Autin, O., Hart, J., Jarvis, P., MacAdam, J., Parsons, S. A. and Jefferson, B. (2013). The impact of background organic matter and alkalinity on the degradation of the pesticide metaldehyde by two advanced oxidation processes: UV/H2O2 and UV/TiO2. Water research 47, 2041-2049.

Breach, R.A. (2011). Drinking Water Quality Management from Catchment to Consumer: A Practical Guide for Utilities Based on Water Safety Plans. IWA, London

Brown, C.D., van Beinum, W. (2009). Pesticide transport via sub-surface drains in Europe. Environmental Pollution, 157, 3314-3324.

Clarke, J. (2009). Evaluation of the impact on UK agriculture of the proposal for a regulation of the European Parliament and of the council concerning the placing of plant protection products on the market. ADAS Boxworth, Cambridge.

Clarke, J., Wynn, S., Twining, S., Berry, P., Cook, S., Ellis, S., \& Gladders, P. (2009). Pesticide Availability for Cereals and Oilseeds Following Revision of Directive 91/414/EEC; Effects of Losses and New Research Priorities. ADAS Boxworth, Cambridge.

Croll, B.T. (1995). The Removal of Pesticides During Drinking Water Treatment. Pesticides: Developments, Impacts \& Controls, 124-134.

Defra, (2012). Appraisal of cost effective policy instruments to tackle the impact from pesticides - WT0963. Defra, London.

Dolan, T., Howsam, P., Parsons, D.J. (2012). Diffuse pesticide pollution of drinking water sources: impact of legislation and UK responses. Water Policy 14, 680-693.

Dolan, T., Howsam, P., Parsons, D.J. \& Whelan, M.J. (2013). Is the EU Drinking Water Directive Standard for Pesticides in Drinking Water Consistent with the Precautionary Principle? Environmental Science and Technology, 47, 4999-5006

DWI. (2010). Guidance on the Implementation of the Water Supply (water quality) Regulations 2000 (as amended) in England. Drinking Water Inspectorate, London

EC. (2012). 2011/0429 (COD): Proposal for a Directive of the European Parliament and of the Council amending Directives 2000/60/EC and 2008/105/EC as regards priority substances in the field of water policy. European Commission, Brussels.

EC. (2003). Scientific Synthesis Report Drinking Water Seminar. European Commission, Brussels

EC. (2009). Regulation 1107/2009 Concerning the Placing of Plant Protection Products on the Market, L 309/1. Official Journal of the European Communities, Brussels. 
EC. (2008). Directive 2008/105/EC on Environmental Quality Standards in the Field of Water Policy, L 348/84. Official Journal of the European Communities, Brussels.

EC. (2000). Directive 2000/60/EC Establishing a Framework for Community Action in the Field of Water Policy, L 327. Official Journal of the European Communities, Brussels.

EC. (1998). Council Directive 98/83/EC on the Quality of Water Intended for Human Consumption, L 330/32 ed. Official Journal of the European Communities, Brussels.

EC. (1991). Council Directive Concerning the Placing of Plant Protection Products on the Market (91/414/EEC), OJ L 230. Official Journal of the European

Communities, Brussels.

EC. (1980). Council Directive 80/778/EEC on the Quality of Water Intended for Human Consumption, OJ L 229. Official Journal of the European Communities, Brussels.

EC. (1979). Council Directive Prohibiting the Placing on the Market and Use of Plant Protection Products Containing Certain Active Substances (79/117/EEC), OJ L 33/36 $e d$. Official Journal of the European Communities, Brussels.

EC. (1975). Directive 1975/440/EEC Concerning the Quality Required of Surface Water Intended for the Abstraction of Drinking Water, L 195. Official Journal of the European Communities, Brussels.

HM Government. (2011). One-In, One-Out (OIOO) Methodology URN 11/761. Department of Business Innovation and Skills, London.

HMSO. (2000). The Water Supply (Water Quality) Regulations 2000. The Stationary Office Ltd, London.

Jordan, A. (1999). European community water policy standards: Locked in or watered down? Journal of Common Market Studies, 37, 13-37.

Keirle, R., Hayes, C. (2007). A review of catchment management in the new context of drinking water safety plans. Water and Environment Journal, 21, 208-216.

Kennedy, J. (2010). Pesticides and the Impact of the Water Framework Directive. $47^{\text {th }}$ BCPC Annual Weed Review.

Kennedy, J., Varma, A., Foo, V. (2009). A study to identify cost-effective measures for plant protection products causing non-compliance with Water Framework Directive objectives (GEHOO109BPGF-E-E.) Environment Agency, Bristol

Clarke, J., Wynn, S., Twining, S., Berry, P., Cook, S., Ellis, S., \& Gladders, P. (2009). Pesticide Availability for Cereals and Oilseeds Following Revision of Directive 91/414/EEC; Effects of Losses and New Research Priorities. ADAS Boxworth, Cambridge. 
Fristachi, A., Xu, Y., Rice, G., Impellitteri, C.A.,Carlson-Lynch, H., Little, J.C. (2009). Using probabilistic modeling to evaluate human exposure to organotin in drinking water transported by polyvinyl chloride pipe. Risk Analysis, 29, 1615-1628.

Knapp, M.F. (2005). Diffuse pollution threats to groundwater: A UK water company perspective. Quarterly Journal of Engineering Geology and Hydrogeology, 38, 39-51.

Moss, S. R. (2010), Non-chemical methods of weed control: benefits and limitations. 17th Australasian Weeds Conference, 26-30 September 2010, Christchurch, New Zealand.

Ofwat. (2011). Capex bias in the water and sewerage sectors in England and Wales - substance, perception or myth? A discussion paper. ISBN 1-904655-91-2. Available at: Ofwat.gov.uk, accessed 26 June 2012

Pollard, S.J.T., Strutt, J.E., Macgillivray, B.H., Hamilton, P.D., Hrudey, S.E. (2004). Risk Analysis and Management in the Water Utility Sector: A Review of Drivers, Tools and Techniques. Process Safety and Environmental Protection, 82, 453-462.

Reichenberger, S., Bach, M., Skitschak, A., Frede, H. (2007). Mitigation strategies to reduce pesticide inputs into ground- and surface water and their effectiveness; A review. Science of the Total Environment, 384, 1-35.

Tediosi, A., Whelan, M. J., Rushton, K. R., Thompson, T. R. E., Gandolfi, C. and Pullan, S. P. (2012). Measurement and conceptual modelling of herbicide transport to field drains in a heavy clay soil with implications for catchment-scale water quality management. Science of The Total Environment, 438, 103-112.

Tediosi, A., Whelan, M.J., Rushton, K.R. and Gandolfi, C. (2013). Predicting rapid herbicide leaching to surface waters from an artificially drained headwater catchment using a one dimensional two-domain model coupled with a simple groundwater model. Journal of Contaminant Hydrology, 145, 67-81.

The Director General of Water Services. (1991). Water Industry Act 1991. Available at: http://www.legislation.gov.uk/ukpga/1991/56/contents, accessed 26 June 2012.

Tizaoui, C., Mezughi, K. and Bickley, R. (2011). Heterogeneous photocatalytic removal of the herbicide clopyralid and its comparison with $\mathrm{UV} / \mathrm{H} 2 \mathrm{O} 2$ and ozone oxidation techniques. Desalination, 273, 197-204.

UKTAG. (2008a). UK Technical Advisory Group on the Water Framework Directive: Proposals for environmental quality standards for annex VIII substances. Available at: http://www.wfduk.org/UK_Environmental_Standards, accessed 26 June 2012.

UKTAG. (2008b). Assessing the Achievement of Drinking Water Protected Area Objectives. Available at: http://www.wfduk.org/tag_guidance/article_4/drinking_water_objectives/view, accessed 26 June 2012. 
UKTAG. (2012). Updated Recommendations on Environmental Standards: River basin management 2015-2021 (Draft). SR3 - 2012. Available at:

http://www.wfduk.org/stakeholders/stakeholder-review, accessed 26 June 2012.

UKWIR (2011). Treatment for new and emerging Pesticides (11/DW/14/4), UKWIR, London.

Warn, A.E., Brew, J.S. (1980). Mass balance. Water Research, 14, 1427-1434.

World Health Organisation. (2011). Guidelines for Drinking-Water Quality, 4 ed. WHO. WHO, Geneva.

Wynn, S., Garstang, P., Gladders, P., Cook, S., Ellis, S., Clarke, J., \& Twining, S. (2009). Crop Protection Priorities for Grass and Forage Crops in Light of Proposed EU Pesticide Regulations and Other Changes. ADAS Boxworth, Cambridge.

\section{Web references}

Directorate General for Health and Consumers (2012). EU Pesticides database. Available at: http://ec.europa.eu/sanco_pesticides/public/index.cfm, accessed 26 June 2012

EC. (2012b). Press Release IP/12/88: Environment and Water: proposal to reduce water pollution risks. Available at:

http://europa.eu/rapid/pressReleasesAction.do?reference=IP/12/88, accessed 26 June 2012.

EC. (2013). WFD Guidance Documents. Available at:

http://ec.europa.eu/environment/water/water-

framework/facts_figures/guidance_docs_en.htm, accessed 04 September 2013.

Metaldehyde Stewardship Group (2012). Get Pelletwise!. Available at:

http://www.getpelletwise.co.uk/ accessed 21 September 2012.

Natural England (2012a). Catchment Sensitive Farming. Available at:

http://www.naturalengland.org.uk/ourwork/farming/csf/default.aspx accessed 21

September 2012.

Natural England (2012b)., Entry Level Stewardship. Available at: http://www.naturalengland.gov.uk/ourwork/farming/funding/es/els/default.aspx accessed 21 September 2012.

The Environment Agency (2012). What's in Your Backyard? Available at: http://www.environment-agency.gov.uk/homeandleisure/37793.aspx accessed 17 October 2012.

The Voluntary Initiative (2011). The Voluntary Initiative: Promoting responsible pesticide use. Available at: http://www.voluntaryinitiative.org.uk/ accessed 21 September 2012. 